\title{
Synthesis of Heterocyclic Compounds by Radical Electrochemical Approach in Environmentally Friendly Media
}

\author{
E. Duñach ${ }^{\mathrm{a}}$, A.P. Esteves ${ }^{\mathrm{b}}$, C.S.S. Neves ${ }^{\mathrm{b}}$, M.J. Medeiros ${ }^{\mathrm{b}}$ \\ ${ }^{a}$ Laboratoire de Chimie Bioorganique, CNRS, UMR 6001, Université de Nice-Sophia \\ Antipolis, Parc Valrose, 06108 Nice Cedex 2, France \\ ${ }^{\mathrm{b}}$ Centro de Química, Universidade do Minho, Largo do Paço, 4704-553 Braga, Portugal
}

Radical cyclisation is rapidly becoming an important method for the formation of cyclic systems. Hence, some electrochemical results obtained in the study of electroreductive intramolecular cyclisation of ethyl 2-bromo-3-(3',4'-methylenedioxophenyl)-3(propargyloxy)propanoate (1) $)$, [1-bromo-2-methoxy-2-(prop-2'-

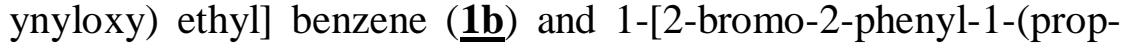
2'-ynyloxy)ethyl]-4-methoxybenzene (두) promoted by $(1,4,8,11$ tetramethyl-1,4,8,11-tetraazacyclotetra-decane)nickel(I), $[\mathrm{Ni}(\mathrm{tmc})]^{+}$, electrogenerated at glassy carbon cathodes in ethanol, ethanol / water and microemulsions made with cationic and anionic surfactants are presented. The results obtained indicate that the reaction proceeds via cleavage of the carbon-bromine bond to form a radical intermediate that undergoes cyclization on the unsaturated $\mathrm{C}-\mathrm{C}$ bond to afford the substituted tetrahydrofurans.

\section{Introduction}

Radical cyclisation continues to appear as one of the central methodologies for the synthesis of natural products containing heterocyclic rings (1). In heterocyclic chemistry most of radical cyclizations are still carried out using tributyltin hydride which is toxic and also troublesome to separate from the reaction products.

A new method involving nickel(I) complexes as mediators in intramolecular cyclizations by indirect electrolysis has been studied in reactions involving aryl and vinyl bromides (2), bromoacetals (3), and $\alpha$-bromoamides (4) with double or triple bonds. This method constitutes a convenient alternative to the tin hydride procedures.

Although most of the electrosynthesis reactions have been carried out in aprotic solvents such as DMF, due to environmental and health issues, the search for non-toxic fluid alternatives to such organic solvents for chemical synthesis would be highly desirable. Compared to organic solvents, water and /or water/alcohol (e.g. EtOH) mixtures are the preferred media for electrosynthesis for both economic and environmental reasons. Another alternative is to employ microemulsions prepared from water, hydrocarbon oils and surfactants, which have attracted wide interest because of their lower toxicity and lower cost as compared to usual organic solvents (5).

In order to evaluate the synthetic scope and limits of the radical cyclisation of compounds 1a-c we have investigated this reaction by indirect electrochemical methods using $\mathrm{Ni}$ (II) macrocyclic complexes as the catalysts in ethanol, and ethanol/water mixtures as well as in microemulsion media using cyclic voltammetry and controlledpotential electrolysis. 
Functionalyzed tetrahydrofurans are important intermediates in the synthesis of natural products such as lignans (6).

\section{Results and Discussion}

The Electrochemistry of the $[\mathrm{Ni}(\mathrm{Tmc})] \mathrm{Br} 2$ Complex in the Absence and in the Presence of Bromoalkoxylated Compounds 1a-c

Cyclic voltammetric studies of solutions of $[\mathrm{Ni}(\mathrm{tmc})] \mathrm{Br}_{2}$ complex in the absence and in the presence of bromoalkoxylated compounds 1a-c were performed at different scan rates at a vitreous carbon electrode in $\mathrm{EtOH}$ and $\mathrm{EtOH} / \mathrm{H}_{2} \mathrm{O}$ mixtures containing $\mathrm{TEABr}$ as supporting electrolyte and in microemulsions made with cetyltrimethylammonium bromide (CTAB), tetradecyltrimethylammonium bromide (MTAB) and sodium dodecylsulfate (SDS) as surfactants.<smiles>[R]C(Br)C([R])OCC#C</smiles>

1a: $\mathrm{R}_{1}=$ ethoxycarbonyl; $\mathrm{R}_{2}=3$,4-methylenedioxophenyl

b: $\mathrm{R}_{1}=$ phenyl; $\mathrm{R}_{2}=$ methoxy

c: $\mathrm{R}_{1}=$ phenyl; $\mathrm{R}_{2}=4$-methoxyphenyl

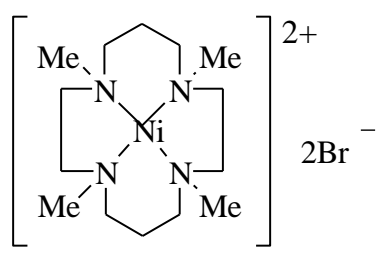

$\mathrm{Ni}(\mathrm{tmc}) \mathrm{Br}_{2}$

Figures 1 (curve B) and 2 (curve B) present the cyclic voltammograms obtained for the reduction of $[\mathrm{Ni}(\mathrm{tmc})] \mathrm{Br}_{2}$ at a vitreous carbon electrode in $\mathrm{EtOH}$ and in CTAB/tetradecane/ $\mathrm{H}_{2} \mathrm{O} / 1$-butanol (17.5/12.5/35/35) microemulsion, respectively.

The figures show that the $\mathrm{Ni}$ (II) complex underwent a reversible one-electron reduction to a stable product and that no further reduction occurred within the potential range of the medium. Formal electrode potentials are -0.86 and $-0.95 \mathrm{~V}$ vs an aqueous $\mathrm{Ag} / \mathrm{AgCl} / 3 \mathrm{M}$ $\mathrm{KCl}$ for $[\mathrm{Ni}(\mathrm{tmc})] \mathrm{Br}_{2}$ in $\mathrm{EtOH}$ and $\mathrm{CTAB} /$ tetradecane/ $\mathrm{H}_{2} \mathrm{O} / 1$-butanol microemulsion, respectively. Similar results were obtained in cyclic voltammetric studies performed in other microemulsions.

Formal electrode potentials were determined in EtOH as well as in several microemulsions and the values are presented in Table 1.

Hence, all the data obtained indicate that the electrode reaction is:

$$
[\mathrm{NiII}(\mathrm{tmc})]^{2+}+\mathrm{e}^{-} \rightleftharpoons[\mathrm{Ni}(\mathrm{tmc})]^{+}
$$

These results are in agreement with those reported previously (7-10) where the added electron is nickel centred and the reduction is fast and occurs without significant changes in the geometry of the complex. 


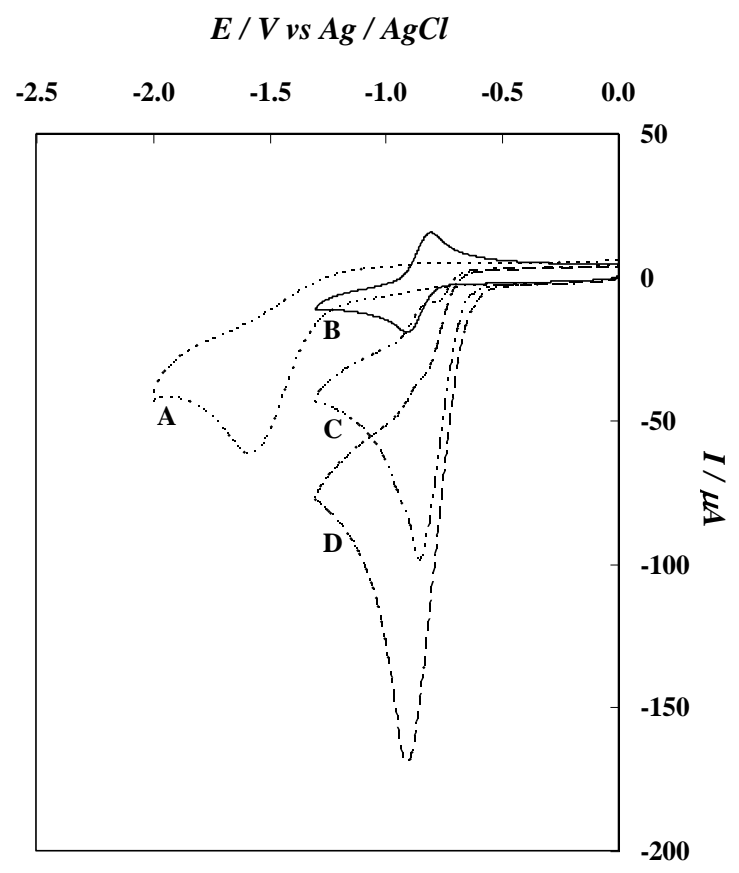

Figure 1. Cyclic voltammograms recorded with a glassy carbon electrode ( $\mathrm{area}=0.07$ $\mathrm{cm}^{2}$ ) at $200 \mathrm{mV} \mathrm{s}^{-1}$ in EtOH containing $0.10 \mathrm{M}$ TEABr: (A) $2 \mathrm{mM} \underline{\mathbf{1 c}}$; (B) $1 \mathrm{mM}$ $[\mathrm{Ni}(\mathrm{tmc})] \mathrm{Br}_{2} ;(\mathrm{C}) 1 \mathrm{mM}[\mathrm{Ni}(\mathrm{tmc})] \mathrm{Br}_{2}$ and $5 \mathrm{mM} \underline{\mathbf{1 c}}$; (D) $1 \mathrm{mM}[\mathrm{Ni}(\mathrm{tmc})] \mathrm{Br}_{2}$ and $10 \mathrm{mM}$ 1c.

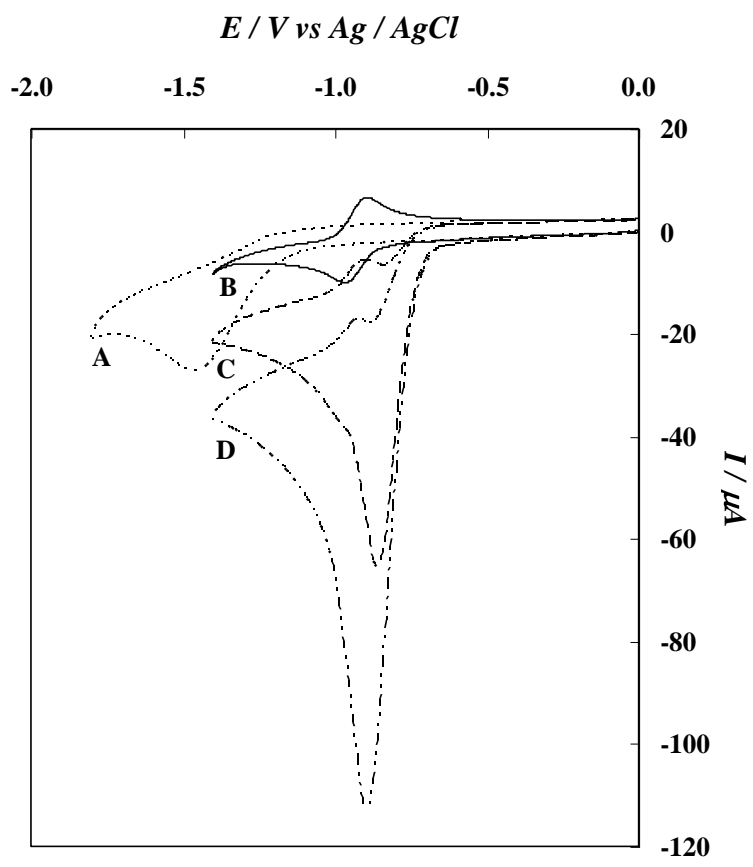

Figure 2. Cyclic voltammograms recorded with a glassy carbon electrode ( $\mathrm{area}=0.07$ $\left.\mathrm{cm}^{2}\right)$ at $200 \mathrm{mV} \mathrm{s}$ in CTAB/tetradecane/ $\mathrm{H}_{2} \mathrm{O} / 1$-butanol $(17.5 / 12.5 / 35 / 35)$ microemulsion: (A) $2 \mathrm{mM} \underline{\mathbf{1 c}}$; (B) $1 \mathrm{mM}[\mathrm{Ni}(\mathrm{tmc})] \mathrm{Br}_{2}$; (C) $1 \mathrm{mM}[\mathrm{Ni}(\mathrm{tmc})] \mathrm{Br}_{2}$ and 5 $\mathrm{mM} \underline{\mathbf{1 c}}$; (D) $1 \mathrm{mM}[\mathrm{Ni}(\mathrm{tmc})] \mathrm{Br}_{2}$ and $10 \mathrm{mM} \underline{\mathbf{1 c}}$. 
Table 1. Standard Redox Potentials for $[\mathrm{Ni}(\mathrm{tmc})] \mathrm{Br}_{2}$ in $\mathrm{EtOH}$ and in Several Microemulsions.

\begin{tabular}{lc}
\hline \multicolumn{1}{c}{ FLUID (wt \%) } & $\boldsymbol{- E}^{\mathbf{o}}(\mathbf{V}) \boldsymbol{v s} \mathbf{A g} / \mathbf{A g C l}$ \\
\hline $0.1 \mathrm{M} \mathrm{TEABr} / \mathrm{EtOH}$ & 0.86 \\
$\mathrm{MTAB}^{\mathrm{a}} / \mathrm{C}_{14} \mathrm{H}_{30} / \mathrm{H}_{2} \mathrm{O} / 1$-pentanol $(17.5 / 12.5 / 35 / 35)$ & 0.95 \\
$\mathrm{CTAB}^{\mathrm{b}} / \mathrm{C}_{14} \mathrm{H}_{30} / \mathrm{H}_{2} \mathrm{O} / 1$-pentanol $(17.5 / 12.5 / 35 / 35)$ & 0.95 \\
$\mathrm{CTAB}^{\mathrm{b}} / \mathrm{C}_{14} \mathrm{H}_{30} / \mathrm{H}_{2} \mathrm{O} / 1$-butanol $(17.5 / 12.5 / 35 / 35)$ & 0.99 \\
$\mathrm{SDS}^{\mathrm{c}} / \mathrm{C}_{14} \mathrm{H}_{30} / \mathrm{H}_{2} \mathrm{O} / 1$-pentanol $(13.3 / 8 / 52 / 26.7)$ & 0.98 \\
\hline
\end{tabular}

a tetradecyltrimethylammonium bromide (MTAB); ${ }^{b}$ cetyltrimethylammonium bromide (CTAB);

${ }^{\mathrm{c}}$ sodium dodecylsulfate (SDS).

The cyclic voltammetric studies of solutions of propargyl 2-bromoethers $\underline{1 a-c}$ in $\mathrm{EtOH}$ and $\mathrm{EtOH} / \mathrm{H}_{2} \mathrm{O}$ containing $\mathrm{TEABr}(0.1 \mathrm{M})$ and in several microemulsions showed that the bromoalkoxylated compounds present a first irreversible reduction wave at potentials near to $-1.50 \mathrm{~V} v s \mathrm{Ag} / \mathrm{AgCl}$, which corresponds to the reductive cleavage of the carbon-bromine bond. Figures 1 (curve A) and 2 (curve A) show the cyclic voltammograms obtained for the reduction of the bromoether $\underline{\mathbf{1 c}}$ at a vitreous carbon electrode in $\mathrm{EtOH}$ and in $\mathrm{CTAB} /$ tetradecane $/ \mathrm{H}_{2} \mathrm{O} / 1$-butanol microemulsion, respectively.

Upon addition of the bromoalkoxylated compounds to the Ni(II) complex mixture, the voltammetric behaviour of the complex changed.

In both media the experiments show that addition of unsaturated halide to the $\mathrm{Ni}$ (II) complex solution results in the increase of the reduction peak height of the mediator as the concentration of the substrate increases and disappearance of the anodic wave. The catalytic current observed is due to the regeneration of the $\mathrm{Ni}$ (II) complex by the chemical sequence. Similar behaviour was observed when these experiments were carried out with other substrates.

Figures 1 (curves $\mathrm{C}$ and $\mathrm{D}$ ) and 2 (curves $\mathrm{C}$ and $\mathrm{D}$ ) present the cyclic voltammograms obtained for the reduction of $[\mathrm{Ni}(\mathrm{tmc})] \mathrm{Br}_{2}$ at a vitreous carbon cathode in the presence of different concentrations of $\underline{\mathbf{1 c}}$ in EtOH/TEABr $\left(\begin{array}{lll}0.10 & \mathrm{M})\end{array}\right)$ and in $\mathrm{CTAB} /$ tetradecane $/ \mathrm{H}_{2} \mathrm{O} / 1$-butanol microemulsion, respectively.

From these figures we can observe that the extent of the catalytic reaction increases when raising $[\mathrm{RBr}]$, for a given mediator concentration.

Controlled-potential Electrolyses of $\mathrm{Ni}(\mathrm{II})$ Complexes in the Presence of Bromoalkoxylated Compounds 1a-c

Table 2 shows the results obtained from the electrolyses of $[\mathrm{Ni}(\mathrm{tmc})] \mathrm{Br}_{2}$ at reticulated vitreous carbon cathode in the presence of $\underline{1}$ in $\mathrm{EtOH}, \mathrm{EtOH} / \mathrm{H}_{2} \mathrm{O}$ mixtures and in several microemulsions; the potential was set at approximately $100 \mathrm{mV}$ after the reduction peak potential of the catalyst in the presence of the unsaturated halide.

In the case of $\underline{\mathbf{1 a}}, \quad 2-\left(3^{\prime}, 4^{\prime}\right.$-methylenedioxophenyl)-3-ethoxycarbonyl-4methylenetetrahydrofuran (2) and 2-(3',4'-methylenedioxophenyl)-3-ethoxycarbonyl-4methyl-2,5-dihydrofuran ( $\underline{\mathbf{3}})$ were formed. It was observed that the number of electrons 
involved per molecule of starting material was approximately one and the total yield of both cyclic compounds was independent of the nature of the medium.

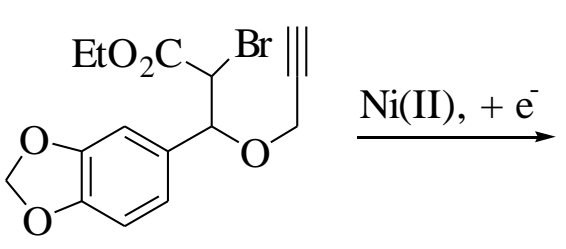

$1 \mathbf{a}$<smiles>C=C1COC(c2ccc3c(c2)OCO3)C1C(=O)OCC</smiles>

2<smiles>CCOC(=O)C1=C(C)COC1c1ccc2c(c1)OCO2</smiles>

3

In the case of $\underline{\mathbf{1 b}}$, the cyclised product, 2-methoxy-4-methylene-3-phenyltetrahydrofuran (4), was formed in quantities from 80 to $99 \%$. It was also seen that the number of electrons per molecule of $\underline{\mathbf{1 b}}$ was one and the yields of the $\underline{4}$ were independent of the nature of the medium.<smiles>C#CCOC(OC)C(Br)c1ccccc1</smiles>

1b

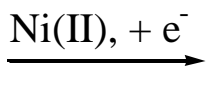<smiles>C=C1COC(OC)C1c1ccccc1</smiles>

4

Finally, in the case of $\underline{\mathbf{1 c}}$, similar results were obtained and 2-(4'-methoxyphenyl)-4methylene-3-phenyltetrahydrofuran (ㅁ) was the sole product formed in yields ranging from 79 to $100 \%$.<smiles>C#CCOC(c1ccc(OC)cc1)C(Br)c1ccccc1</smiles>

1c<smiles>C=C1COC(c2ccc(OC)cc2)C1c1ccccc1</smiles>

5

In conclusion : (i) The experimental results presented suggest that the catalytic electroreductive cyclization of the bromoethers $\underline{1}$ catalized by $[\mathrm{Ni}(\mathrm{tmc})] \mathrm{Br}_{2}$ complex in $\mathrm{EtOH}, \mathrm{EtOH} / \mathrm{H}_{2} \mathrm{O}$ and microemulsions to afford cyclic compounds can be accomplished; (ii) the yields of the cyclic ethers are good enough to make this procedure an alternative to other synthetic methods; (iii) an advantage of this method is the radical reactions can be carried out using a catalytic amount of a complex of an appropriate metal at room temperature in environmentally friendly media. 
Table 2. Coulometric Data and Product Yields for Catalytic Reduction of $\underline{1 a}, \underline{1 b}$, and $\underline{1 \mathrm{c}}$ by $[\mathrm{Ni}(\mathrm{tmc})]^{+}$Electrogenerated at Reticulated Vitreous Carbon or Graphite Felt Cathodes in EtOH and in Several Microemulsions. [RBr] / [Ni(II)] = 10 .

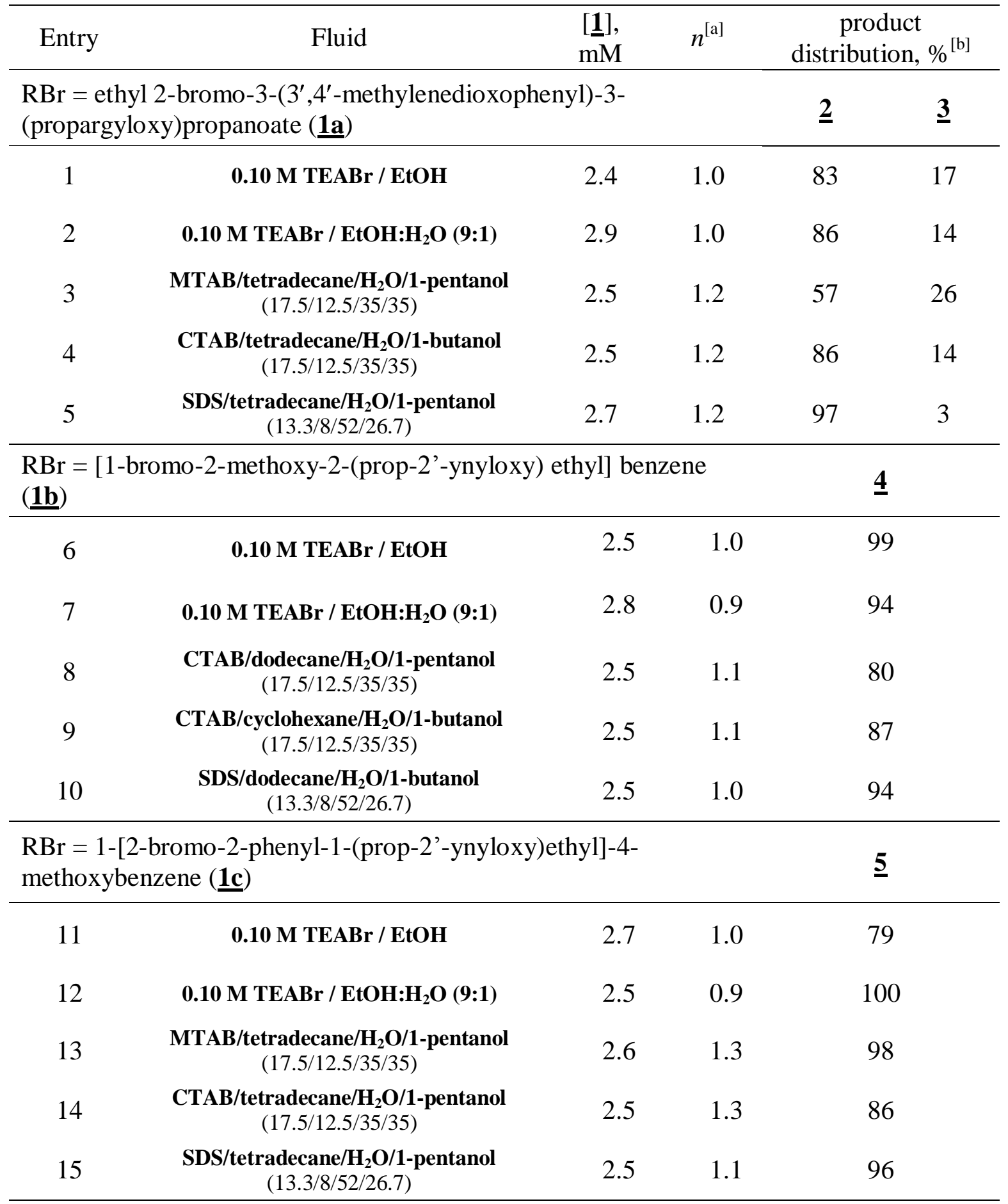
${ }^{[a]}$ Number of electrons per molecule of starting material. ${ }^{[b]} \%=$ yield expressed as the percentage of $\underline{\mathbf{1}}$
incorporated into each product. 


\section{Acknowledgments}

We are grateful to the Fundação para a Ciência e Tecnologia and FEDER for financial support of this work (PPCDT/QUI/55576/2004).

\section{References}

1. B. Giese, "Radicals in Organic Synthesis: Formation of Carbon-Carbon Bonds", Pergamon Press, Oxford (1986).

2. S. Ozaki, E. Matsui, J. Waku, H. Ohmori, Tetrahedron Lett., 38, 2705 (1997); (b) S. Olivero, J.-P. Rolland, E. Duñach, Organometallics, 17, 3747 (1998) (and references cited therein).

3. S. Ozaki, H. Matsushita and H. Ohmori, J. Chem. Soc., Chem. Commun., 1120 (1992).

4. M. Ihara, A. Katsumata, F. Setsu, Y. Tokunaga and K. Fukumoto, J. Org. Chem., 61, 677 (1996).

5. M. Bourrel, J.F. Rusling, "Microemulsions and Related Systems", Marcel Dekker, New York (1988); J.F. Rusling, in: B.E. Conway, J.O’M. Bockris (eds.), "Modern Aspects of Electrochemistry", pp.49-104, No. 26, Plenum, New York (1994).

6. P.K. Mandal, G. Maiti, S.C. Roy, J. Org. Chem., 63, 2829 (1998).

7. J.Y. Becker, J.B. Kerr, D. Pletcher, R. Rosas, J. Electroanal. Chem. 117, 87 (1981).

8. C. Gosden, J.B. Kerr, D. Pletcher, R. Rosas, J. Electroanal. Chem. 117, 101 (1981).

9. C. Gosden, D. Pletcher, J. Organometal. Chem. 186, 401 (1980).

10. C. Gosden, K.P. Healy, D. Pletcher, J. Chem. Soc., Dalton Trans. 972 (1978). 